\title{
GUERRA NO LIVRO ILUSTRADO INFANTIL: A CAMINHO DE CASA, DE ANA TORTOSA E ESPERANZA LEÓN
}

\author{
Thiago Alves Valente (UENP-Cornélio Procópio) \\ Eliane Aparecida Galvão Ribeiro Ferreira (UNESP)
}

Resumo: Este artigo objetiva refletir sobre o tema da guerra manifesto no livro ilustrado infantil contemporâneo. Para tanto, elegeu-se a obra $A$ caminho de casa, escrita por Ana Tortosa e ilustrada por Esperanza León (2012), pois permite um modo de representação cativante, segundo Linden (2011), pela percepção simultânea de dois textos distintos: verbal e imagético. Justifica-se, então, na análise dessa obra, refletir sobre suas potencialidades na formação do leitor crítico (ECO, 2003). Para tanto, busca-se a partir do aporte da Estética da Recepção (JAUSS, 1994; ISER, 1996 e 1999), detectar se há vazios na estruturação da obra, que geram expectativa e tensão, bem como potências de negação e silenciamentos, os quais suscitam revisões de hipóteses, enfim, produtividade do leitor na leitura. Além disso, se suas ilustrações possuem pregnância estética (OLIVEIRA, 2008), sendo capazes de ampliar o imaginário do leitor infantil, constituir sua memória afetiva e, assim, desautomatizar seu olhar em relação à imagem.

Palavras-chave: Livro ilustrado; Formação do Leitor; Estética da Recepção.

Abstract: This paper aims to reflect on the war theme represented in a contemporary children's illustrated book. For this reason, the work $A$ caminho de casa, written by Ana Tortosa and illustrated by Esperanza León (2012), was chosen because it allows a captivating mode of representation, according to Linden (2011), by the simultaneous perception of two distinct texts: verbal and imagery. Therefore, it is justified to reflect on its potentialities in the formation of the critical reader (ECO, 2003) in its analysis. Thus, it seeks, from the contribution of the Reception's Aesthetics (JAUSS, 1994; ISER, 1996 and 1999), to detect if there are gaps in the work structuring, which generate expectation and tension, as well as negation powers and silences, that provoke reviews of some hypotheses, in short, the reader's productivity in reading. In addition, if its illustrations have aesthetic visual impact 
(OLIVEIRA, 2008), being able to enlarge the child's reader's imagination, constitute his/her affective memory and, then, deactivate his/her view regarding the image.

Keywords: Illustrated book; Reader training; Reception's Aesthetics.

\section{INICIANDO A JORNADA}

Nos anos 1990, no Brasil, o livro ilustrado apresentavase como gênero inovador e em constante diálogo tanto com o universo das artes plásticas, quanto com o da indústria cultural. Em 2000, esse livro revelou-se como obra pósmoderna, híbrida e intertextual. Em 2008, merece destaque ao se tornar objeto de pesquisas, de estudos e de discussões em simpósios, como os da Associação Brasileira de Literatura Comparada - ABRALIC. Cabe destacar que, também, passou a ser contemplado nos editais do Programa Nacional Biblioteca da Escola - PNBE ${ }^{1}$, visando à composição de acervos.

O tratamento literário de temática fraturante - termo empregado por Ana Margarida Ramos e Diana Navas (2015) - é próprio da produção contemporânea que prevê um leitor desejoso por encontrar temas de seu tempo, que lhe facultem refletir sobre diferentes formas de vida. A literatura, assim, almeja sintonizar-se com o tempo a que pertence e com seu leitor, para tanto, em seu processo de construção, busca conscientizá-lo em relação às descobertas que lhe cabe

1 Este Programa foi suspenso em 2014, mas seus acervos permanecem nas bibliotecas das escolas públicas do nosso país. 
fazer no mundo. O imaginário é visto como instrumento de conquista do conhecimento de si e do mundo em que se vive.

Entre as obras ilustradas que compõem os acervos do PNBE, cujos temas são fraturantes, situa-se $A$ caminho de casa, escrita em versos por Ana Tortosa e ilustrada por Esperanza Léon (2012). No contexto desse Programa, a obra foi enquadrada nos acervos de 2013 destinados às séries finais do Ensino Fundamental II (PORTAL MEC, 2020). Neste artigo, contudo, entende-se que se destina ao público infantil, sobretudo, pelo seu "eu lírico" ser retratado como uma menina. Para melhor caracterizarmos a obra, recorremos às definições de Sara Reis da Silva sobre o "álbum poético" narrativo. Para a estudiosa, esse tipo de livro híbrido congrega versos e imagens em um objeto estético coerente que fomenta inúmeras leituras, as quais

podem ser concretizadas ao ritmo pessoal de cada destinatário extratextual, pelo facto do seu conteúdo se estender de forma progressiva, com sobriedade e contenção, formando uma mancha gráfica inovadora. [...]. Do ponto de vista gráfico e/ ou paratextual, é possível, ainda, distinguir os volumes a que nos referimos pelo número reduzido de páginas, pela capa dura, pela impressão em papel de alta gramagem e pelo design cuidadoso e original.

(SILVA, 2010, p.565-66) 
Neste artigo, optamos pela terminologia "livro ilustrado", em consonância com Maria Nikolajeva e Carolle Scott (2011, p.329), como aquele que oferta dupla audiência, conferindo poder de modo igualitário a crianças e adultos, já que são projetados para serem lidos ao mesmo tempo, por meio de palavras, imagens e pela combinação entre elas. Essa igualdade avulta no processo de leitura, pois enquanto o texto verbal se dirige ao adulto e requer um olhar linear, a imagem se dirige à criança, solicitando um olhar holístico. A folha dupla, pela oferta de simultaneidade dos dois processos, faculta à criança eleger seu próprio ritmo. Essa percepção da criança suplanta a do adulto, segundo Duvoisin (apud HUNT, 2010, p.241), pelo fato de que ela vê o mundo de forma desinibida, diversa dos mais velhos. Nesse processo de leitura mediada do livro ilustrado, criança e adulto podem, então, ampliar seus olhares.

A caminho de casa (2012) oferta essa dupla audiência. Sua escritora, Ana Tortosa, nasceu na Cantábria, no norte da Espanha, possui vários livros ilustrados para o leitor mirim e juvenil, e recebeu um prêmio, em 2002, em um concurso de contos, conforme informações no próprio livro (TORTOSA, 2012²). A ilustradora, pintora e gravurista Esperanza León (1956-) é formada em Belas Artes pela Universidad

2 Não há informações na web sobre sua data de nascimento ou formação. 
Complutense de Madrid. Atua em revistas, jornais, textos científicos de botânica e para diversas editoras. Também, participa com suas pinturas e gravuras de exposições individuais e coletivas. Possui obras em coleções públicas e privadas na Espanha, França, Suíça, Cuba, entre outros países (ARTELISTA, 2020; TORTOSA, 2012).

Na análise da obra (2012), pretende-se refletir sobre suas potencialidades na formação do leitor crítico (ECO, 2003). Para tanto, busca-se, a partir do aporte da Estética da Recepção (JAUSS, 1994; ISER, 1996 e 1999), detectar se há vazios na sua estruturação, que geram expectativa e tensão, bem como potências de negação e silenciamentos, os quais suscitam revisões de hipóteses, enfim, a produtividade do leitor. Além disso, se suas ilustrações possuem pregnância estética, a qual, segundo Rui de Oliveira (2008), é capaz de ampliar o imaginário do leitor infantil, constituir sua memória afetiva e, assim, desautomatizar seu olhar em relação à imagem.

\section{POR ENTRE ESCOMBROS}

A obra A caminho de casa (2012) faz uso de convenções da literatura e das artes plásticas canônicas, bem como contemporâneas. Desse modo, segundo Linda Hutcheon (1991), ela diminui o hiato entre as formas artísticas altas e 
baixas. Nesse livro, há experimentação na materialidade e a relação entre texto verbal e imagético se estabelece pela interação na folha dupla, exercendo "função de colaboração", pois o sentido não emerge só das imagens ou do plano verbal, antes da relação entre os dois, pois um preenche as lacunas do outro (LINDEN, 2011). A representação nessa folha propõe uma leitura que considera a abertura do livro como suporte expressivo, capaz de escapar ao movimento usual de encadear páginas na leitura, rompendo assim com os conceitos prévios do leitor e fomentando a ampliação de seu horizonte de expectativa (ISER, 1996 e 1999).

Para compreender algo de um mundo brutalmente modificado pela guerra, a voz poética em seu texto verbal busca sintonia com o olhar de crianças cujos lares foram e são varridos por conflitos bélicos. O texto dialoga, pois, com relatos de guerras, sobre os quais José Otaviano Silva aponta duas formas de abordagens a partir dos personagens, "homefront orphans" e "battlefront orphans":

By "homefront orphans" I mean those children who did not actually experience the war first hand, for the wars their fathers were involved in were waged in foreign lands. Stories of American children whose fathers were killed in the Second World War or the Vietnam War are typical examples. [...] 
The "battlefront orphans", on the other hand, are those children that have witnessed war in their home countries, have seen their towns raided, their schools bombed, their relatives taken as prisoners and, of course, their parents killed - often in front of them. Orphans of occupied countries (from France to Lebanon, from Poland to Vietnam, all around the world) fall into this category. (2016, p.17)

Na obra em análise, ao leitor se presentificam as perdas das crianças em um espaço marcado pela guerra que, supostamente, já passou ou mesmo cessou ali, inscrevendoas sob a ideia de "battlefront orphans". A figuração da jornada se configura de modo intimista, o que se sustenta pela poeticidade do texto verbal e, sobretudo, pelo texto imagético, pautado pela função narrativa, a qual se orienta para o referente, situa o representado e suas transformações ou ações, assegurando a progressão discursiva, conforme estudos de Luís Camargo (1998).

Em sua configuração sob a forma de aquarela, as ilustrações de Esperanza León (2012) aproximam-se dos quadros impressionistas pela presença sutil de contrastes e transparências que concorrem para o desvanecimento da forma e homogeneização da paisagem; pela diluição de seus elementos e contornos; pelas texturas, promovidas por camadas de tinta sobrepostas; pela manutenção de 
uma mesma gama cromática e de matizes sutis da luz, que evocam a técnica de artistas como J. M. W. Turner (17751851), Alfred Sisley (1839-1899) e Claude Monet (1840-1926). Nesse diálogo com as artes plásticas, León apropria-se do recurso impressionista de captura do instante cotidiano e do movimento, contudo, pelo viés paródico, afasta-se dele na subversão do uso das cores e dos materiais. Em suas imagens, embora a luz se faça presente, prevalecem tonalidades lúgubres e tons escuros em várias cenas, evocando o emprego de carvão e água, perpassado pela tecnologia de impressão gráfica.

Desse modo, abusa da cor preta e cinza, em diferentes nuances, além da violeta e roxa, evocando sensações de dor, tristeza, solidão, medo, silêncio e desamparo (FARINA; PEREZ; BASTOS, 2006). A ilustradora subverte a sensação de paz e tranquilidade que quadros, como os de Sisley e Monet, evocam no leitor, afinando-se à paradoxal produção pós-impressionista de Gwendolen Mary John (1876-1939), que concilia delicadeza e neurose cultural - na acepção de José Paulo Paes (1985), como fruto da constatação do homem da falta de controle sobre as coisas. León utiliza-se, assim como John, em alguns de seus quadros, de cores em tons pastéis, que contrastam muito pouco entre si, o que 
colabora com a sensação de desânimo, desamparo e tristeza. Além disso, opta pela ilustração sangrada, conotando que as cenas - dispostas em folha dupla -, poderiam prosseguir indefinidamente, pois não há margens para contê-las.

Sua opção pela diluição da paisagem e de traços inclusive humanos é coerente com o tema da guerra que provoca o exílio, o descentramento do sujeito, pela ruptura de fronteiras geográficas, morais e éticas, em que a existência torna-se difusa. Condizente com a temática, a experimentação da materialidade prevalece no livro e pode ser notada pelo emprego de perspectivas diversas e de bricolagens em algumas cenas; pela escolha do formato que confere amplitude ao drama disposto ao olhar do leitor com 21,5 cm de largura e $30 \mathrm{~cm}$ de altura -; pela ausência de fólios, impedindo a ruptura com o imagético; pela configuração das capas metapictóricas, que simulam rasgos nas margens, como que provocados pelo fogo, revelando a textura e cor que compõem as folhas de guarda. Essas folhas, por sua vez, pela abstração das formas, cores em tons pastéis, bem como disposição dos elementos, evoca um cenário citadino devastado, visto do alto. A cor branca que compõem a paisagem dessas folhas, configurada em ocre, produz o vazio, que evoca a radiografia favorável à precisão 
de um avião bombardeiro, mas desfavorável à vida. Reforça essa ideia a mancha difusa e escura sobre um ponto negro no canto direito da folha dupla, simulando a queda de uma bomba e sua devastação.

As folhas de guarda, por sua vez, também são margeadas por uma linha vertical marcada a fogo. Essa mesma linha aparece na folha que antecede a de rosto, revelando a diluição de fronteiras no projeto gráfico da obra, mimetizando o avanço da guerra que, no relato, a tudo destrói e desintegra. Pode-se notar que, tanto nas capas, quanto nas folhas de guarda, as funções lúdica e metalinguística (CAMARGO, 1998) são empregadas, pois a imagem apresenta-se sob a forma de um jogo e está orientada para o próprio código visual, por isso precisa ser desvendada pelo leitor, requer sua produtividade (JAUSS, 1994; ISER, 1996 e 1999).

$\mathrm{Na}$ obra, as capas promovem a reflexão sobre a constituição de uma história, invadida pela violência e destruição bélica, representadas nas folhas de guarda. Estas folhas, pautadas pelo vazio e, mesmo assim, capazes de adentrar as capas, desalojam o olhar habituado a margens estanques, suscitando interação com o leitor em busca de concretude. Tanto a capa, quanto a quarta capa completamse na representação de um cenário desolador em que 
caminha uma menina e seu cão. Essa personagem, com uma boina e camadas de roupas sobrepostas, além de sacolas nas mãos, rosto voltado para o chão e semblante triste, evoca a criança desamparada que, em um cenário de clima frio, está em movimento, pois é imigrante, despatriada. Sem lugar fixo para residir, ela carrega consigo tudo que possui, na companhia de um animalzinho desvalido, como ela. Essa ilustração aparece na folha de rosto e na etapa final da história, no momento em que a narradora afirma que, um dia, a normalidade regressará (2012, p.34-35³). Nota-se, contudo, nessa cena, a ausência do cão, evocando que o animal não resistira à jornada de retorno para casa. Reforça essa hipótese a cena seguinte e final (p.40-41) em que se vê, apenas, a cabeça do cachorro (p.41), com o restante de seu corpo encoberto pela poeira da paisagem. Essa imagem também aparece na página do final do livro (p.42), contudo, margeando-a verticalmente à esquerda, conotando que paralela à história da narradora há a de outros seres que sofreram com a guerra.

A função expressiva (CAMARGO, 1998) permeia os rostos representados na obra, não só do "eu lírico" da capa, mas de todos outros seres humanos, manifestando suas emoções de

3 Não há fólios na obra, desse modo, o que apresentamos neste texto resulta da nossa contagem das páginas. 
espanto, desolação e abatimento, mas também, no caso de uma criança, de esperança (2012, p.20-21). Nesta cena, em folha dupla, na página da esquerda (p.20), ilustram-se alguns homens que caminham e tentam se localizar em meio a escombros; na da direita (p.21), uma menininha abraça-se a um filhote de cachorro, sem entender o que acontece ao seu redor. A fragilidade desses dois seres evoca a comoção no leitor, pela percepção de que Ihes foi sequestrado o direito à alegria e proteção, ao carinho, enfim, à infância. Pela leitura da obra, pode-se deduzir que se trata da mesma menina e de seu cão que aparecem na capa, contudo, mais novos ainda. O que indica a prolongada duração da guerra. Ao final do relato, a cena de uma jovem sentada ao pé de uma árvore (p.40-41) evoca que a menina cresceu e conquistou o direito à leitura e à arte, em especial, espanholas e engajadas, pois, ao tratarem da guerra e de governos opressores, denunciamnos, promovendo o desejo no leitor de mudança social e política, de relações mais humanas e equânimes. Justificase, então, que ela folheie um livro e ao seu redor haja outros, como um sobre Goya (1746-1828) e uma antologia do poeta e dramaturgo Miguel Hernández (1910-1942). Vale destacar que, no poema, não se trata dessa cena, indicando a autonomia da ilustração e sua competência na constituição autônoma de sentidos que avançam em relação ao texto 
verbal. A estrofe que colabora com essa cena afirma a futura conquista: "E voltaremos a nos sentir livres, / ainda que sem entender / tudo o que aconteceu" (p.41).

Suas ilustrações, coerentes com as performances de sujeitos que vivenciaram a guerra e, por causa dela, foram afastados de seus lares e, agora, perambulam por espaços irreconhecíveis, pautados por escombros, caracterizam-se pelo movimento, exercendo função narrativa (CAMARGO, 1998). Elas se assemelham ao poema com que dialogam, pois este também se configura pela captura de instantes ora vazados pela narratividade, ora pela subjetividade. Essas ilustrações remetem à aquarela e apresentam função estética (CAMARGO, 1998), pois destacam a configuração visual, com o objetivo de sensibilizar, por meio de sobreposições de cores e alternâncias de tons. Como elas predominam em relação ao texto verbal, sendo constante sua aparição na folha dupla, as estrofes ora aparecem na página da esquerda, ora na da direita, ora na parte de cima, ora na de baixo, provocando o olhar infantil habituado à previsibilidade. Ademais, em algumas cenas desaparecem (2012, p.18-19; p.28-29), instaurando o silêncio e conotando que as imagens bastam para a construção de sentidos na obra.

A função narrativa das ilustrações estabelece homologia como poema, pautado pelo prosaico. Acaptura do sentimento 
de perda e de busca se constrói, então, pela nominação inicial de palavras/objetos que ancoram a memória do que havia ali antes da destruição. É assim que ao banco da praça se vincula a primeira referência de memória, qual seja, dos velhos que ali se sentavam "ao sol nas tardes mornas de primavera" $(2012$, p.5).

Da mesma forma, a caixa de correio é aquela que "abrigava as cartas de amor" (2012, p.7); e o parque era "repleto de crianças, brincadeiras e liberdade" (p.9). A escola, além de toda branca - contraponto verbal à imagem cinzenta do pós-guerra, sobre a qual a escrita é registrada - "cheirava a livros e lápis de cor" (p.11). O apelo sinestésico aproxima o leitor infantil da vivacidade de cenas a serem imaginadas, mas não vistas, pois a guerra levara as cores, os sons, os cheiros - à árvore, atribui-se o papel de acolhimento da vida, pois nela havia um "ninho de pássaros" (p.12). Alçada a símbolo de vida, a água também se vai com a ausência da fonte que "matava nossa sede em dias verão" (p.15), clima intensificado pelo amarelo árido das páginas. O presente, então, se impõe: "Agora minha casa está em ruínas", continuando: "Destruíram o caminho que levava até ela. / Não há mais bancos nem tardes de primavera. / Não há mais caixas de correio nem cartas de amor" (p.16). Em síntese, 
pela potência de negação, a qual nega, mas sem apagar o referente (ISER, 1999), convoca-se o leitor a interpretar o que não mais existe, comparando com o que havia antes da guerra: convívio, amor, liberdade e diversão, ensinamentos, vida e partilha de bens naturais.

Em outra página, retomando a desertificação causada pela guerra, outro clamor: "Não poderemos matar nossa sede na mesma fonte" (p.24). Pode-se notar que o "eu lírico", como recurso de retórica, promove a reiteração em seu discurso em níveis diversos: fonológico (pelas assonâncias e aliterações); léxico (pela repetição de vocábulos); sintático (pela estrutura paralelística). Vale destacar que a repetição intensifica a expectativa e tensão para o leitor. Pela potência de negação e sua reiteração, manifesta na expressão do que "não há mais", o eu lírico, paradoxalmente, afirma dados sobre seu futuro. Assim, expressa que, "nunca mais", poderá rever a escola e a árvore com "seu ninho de pássaros", também não conseguirá saciar a sede "na mesma fonte". Apesar disso, afirma que há esperança, pois resta a inocência das crianças, que não entendem o que aconteceu (2012):

Eu pensava que a realidade era apenas um pesadelo, mas as lágrimas tiraram toda a poeira de meus olhos. (p.27) 
O caminho de casa

agora é um lugar de escombros,

de dor, de vazio, de silêncio. (p.30)

Algum dia

há de haver, novamente

um caminho que leve a alguma casa. (p.32)

Nele haverá um banco,

uma caixa de correio, (p.35)

um parque,

uma escola, (p.36)

uma árvore,

uma fonte... (p.38)

E voltaremos a nos sentir livres, ainda que sem entender tudo o que aconteceu. (p.41 - grifos nossos)

Esses elementos, todos marcados por caracterizações inscritas de modo positivo, são substituídos pelo que há, agora, com a passagem da guerra: a negação daquelas coisas intimamente ligadas à vida cotidiana, privada e social, que ensejam um lamento finalizado por um apelo de esperança.

\section{AO FIM DO CAMINHO}

Como se pode notar, escritora e ilustradora (2012) imprimem o poético na ilustração e a narratividade no poema, subvertendo fronteiras textuais diversas e incorporando as inovações da produção contemporânea, cuja tônica recai, conforme Yves Stalloni, na "aspiração à liberdade" (2001, p.168). A escansão silábica também é um elemento que sustenta a visão da narratividade no poema, 
o qual se apresenta com alternâncias das sílabas poéticas e das rimas, sugerindo um tom prosaico, de fácil assimilação, aproximando o texto ao ato de narrar. Outro fator relevante no poema que o direciona ao narrativo é a presença de traços da oralidade, exercendo o movimento de associar o texto literário ao prosaico.

Frente a essas considerações, torna-se relevante, ainda, lembrar o lugar social ocupado pela literatura produzida para crianças. Conforme apontam Elena Elsa Stapich e Mila Alicia Cañon (2011), a inevitável escolha temática, estilística e ideológica está imbricada no fazer do escritor, o que se soma às instâncias da escola e do mercado, num circuito que, ao crítico, impõe a responsabilidade de pensar essa produção:

Este canon literario móvil y cambiante, filtrado por intenciones extraliterarias, atravesado por operaciones de manipulación con fines económicos, ideológicos, didácticos y además literarios, es el que, en la primera infancia, construirá la autobiografía de lecturas de los niños, especialmente aquellos que tengan la oportunidad de concurrir a la escuela y cuando en ella se construya "la ocasión" para compartir libros entre lectores en escenas de lecturas perdurables; muchos de ellos poseerán este recuerdo de lo literario para el resto de sus vidas, no serán docentes, profesores de literatura, alumnos universitarios, críticos, o sea, no pertenecerán a la cofradía microscópica de 
lectores profesionales; habrán alimentado su patrimonio de lecturas, su imaginario y su autobiografía lectora a partir de esta oferta escolar. Entonces, si la lectura es parte del capital simbólico que la escuela debe legar, ¿puede soslayar este compromiso?

(STAPICH, CAÑON, 2011, p.4)

Frente ao artefato literário que convida o jovem à vivência e consequente sensibilizaçãopara com o tema "guerra", correlacionado à "infância", cabe observar a instauração de um discurso antibelicista, ou mesmo de denúncia, suscitado ao longo do texto e explicitado de modo indelével ao final. O tema, portanto, situa-se na perspectiva levantada pelas autoras:

Se trata de un fenómeno global, que se manifiesta por la inclusión en los catálogos editoriales de colecciones completas destinadas a ofrecer a niños y adolescentes textos dirigidos a promover conductas solidarias, cuidado del medio ambiente, actitudes favorables a la no discriminación racial y religiosa, preservación de la salud frente a peligros tales como el abuso de drogas o la anorexia, igualdad de los géneros, etc. Es decir, un conjunto de ideologemas que tienden a la homogeneización de las subjetividades, a través del pensamiento "políticamente correcto". (STAPICH, CAÑON, 2011, p.6)

A aceitação da premissa de que há uma visada ideológica universalmente aceita coloca à crítica o desafio de valoração 
de textos diversos, todos "bem intencionados", como quer Peter Hunt (2010). O valor literário destacado em uma obra como A caminho de caso (2012), enfim, merece atenção justamente pelas escolhas estéticas das autoras que, sem subestimar o público infantil, deixam a dura experiência da guerra como espaço de construção da alteridade diante do mundo que o espera.

\section{REFERÊNCIAS}

ARTELISTA (2020). In https://esperanzaleon.artelista.com. Acesso em 10.Jan.2020.

CAMARGO, Luís H. de. Poesia infantil e ilustração: estudo sobre $\mathrm{Ou}$ isto ou aquilo de Cecília Meireles. 214 p. Dissertação de Mestrado pela Universidade estadual de Campinas - UNICAMP, São Paulo, 1998.

ECO, Umberto (2003). Sobre literatura. Rio de Janeiro: Record.

FARINA, Modesto; PEREZ, Clotilde; BASTOS, Dorinho (2006). Psicodinâmica das cores em comunicação. 5.ed. (Rev. Ampl.) São Paulo: Edgard Blücher Ltda.

HUNT, Peter (2010). Crítica, teoria e literatura infantil: Peter Hunt. Cid Knipel (Trad.). São Paulo: Cosac Naify.

HUTCHEON, Linda (1991). Poética do pós-modernismo: história, teoria, fiç̧ão. Trad. Ricardo Cruz. Rio de Janeiro: Imago.

ISER, Wolfgang (1996). O ato da leitura: uma teoria do efeito estético. Vol.1. Johannes Kretschmer (Trad.). São Paulo: Ed. 34.

(1999) O ato da leitura: uma teoria do efeito estético. Vol.2. Johannes Kretschmer (Trad.). São Paulo: Ed. 34.

JAUSS, Hans Robert (1994). A história da literatura como provocação à teoria literária. Sérgio Tellaroli (Trad.). São Paulo: Ática.

LINDEN, Sophie Van der (2011). Para ler o livro ilustrado. Dorothée de Bruchard (Trad.). São Paulo: Cosac Naify. 
NIKOLAJEVA, Maria; SCOTT, Carole (2011). Livro ilustrado: palavras e imagens. Cid Knipel (Trad.). São Paulo: Cosac Naify.

OLIVEIRA, Rui de (2008). "Breve histórico da ilustração no livro infantil e juvenil". In: OLIVEIRA, leda de (Org.). O que é qualidade em ilustração no livro infantil e juvenil: com a palavra o ilustrador. São Paulo: DCL, p.13-47. PAES, José Paulo (1985). "A verdadeira história de Frankenstein". In: . Gregos \& baianos: ensaios. São Paulo: Brasiliense, p.231-241.

PORTAL MEC. In http://portal.mec.gov.br/index.php?option=com docman\&view=download\&alias=13992-pnbe-2013-seb-pdf\&category slug=setembro-2013-pdf\&Itemid=30192 Acesso em 10.Fev.2020.

RAMOS, A. M.; NAVAS, D. (2015). "Narrativas juvenis: o fenómeno crossover nas literaturas portuguesa e brasileira". Elos: Revista de Literatura Infantil e Xuvenil, (2), 233-256.

SILVA, José Otaviano da Mata (2016). The presente of the past: representation of war, testimony and ideology in $20^{\text {th }}$ and $21^{\text {st }}$ century war orphan narratives. (Dissertação - Mestrado). Universidade Federal de Minas Gerais. Belo Horizonte: UFMG/FALE.

SILVA, Sara Reis da (2010). "Ilustração e Poesia: para uma definição/ caracterização do álbum poético para a infância". In: Actas do I Congreso Internacional Arte, Ilustración y Cultura Visual en Educación Infantil y Primaria: Construcción de Identidades. Granada, p.565-570. In http://hdl. handle.net/1822/22081 Acesso em 24.Mar.2020.

STALLONI, Yves (2001). Os gêneros literários. Flávia Nascimento (Trad. e Notas). Rio de Janeiro: Difel.

STAPICH, Elena Elsa (2011). "Cañon, Mila Alicia. Infancia, lectura y mercado". Revista Pilquen (14), Viedma, jan./jun. In http://www.scielo.org.ar/scielo. php?script=sci_arttext\&pid=S1851-31232011000100016\&lang=pt Acesso em 23.Mar.2020.

TORTOSA, Ana (2012). A caminho de casa. Esperanza Léon (llustr.). Márcia Leite (Trad.). São Paulo: Edições Jogo de Amarelinha. 
Thiago Alves Valente é Graduado em Letras, habilitação em Língua Portuguesa, Alemã e Inglesa, e respectivas literaturas, pela Universidade Estadual Paulista Júlio de Mesquita Filho (UNESP-Assis), em 2001. Pósgraduação na área de "Literatura e vida social": Mestrado em Letras pela UNESP-Assis, em 2004; Doutorado em Letras pela UNESP-Assis, em 2009. Atualmente é professor da Universidade Estadual do Norte do Paraná (UENP-Cornélio Procópio), desenvolvendo atividades de pesquisa com iniciação científica de graduandos e especialistas e participando do grupo de pesquisa Crítica e Recepção Literária (CRELIT). Atua principalmente nos seguintes temas: Literatura Infantil/Juvenil Brasileira, Teoria Literária e Metodologia do Ensino de Língua Portuguesa.

Eliane Aparecida Galvão Ribeiro Ferreira é Professora assistente da Faculdade de Ciências e Letras da Universidade Estadual Paulista "Júlio de Mesquita Filho" (UNESP), Câmpus de Assis (SP); doutora em Letras pela UNESP, Câmpus de Assis na área de Literaturas de Língua Portuguesa, linha de pesquisa em Literatura e Vida Social. Possui experiência nas áreas de Literatura, Leitura e Ensino, com ênfase em Formação do Leitor. É membro dos grupos de pesquisa "Leitura e Literatura na Escola" (UNESP - Assis - SP); "Literatura Infantil e Juvenil: análise literária e formação do leitor" (UTFPR - Curitiba - PR); "RELER - Grupo Interinstitucional de Pesquisa em Leitura" (PUC-Rio); e "A narrativa ficcional para crianças e jovens: teorias e práticas" (UERJ), e do Grupo de Trabalho "Leitura e Literatura Infantil e Juvenil", junto à ANPOLL. 